\title{
Intercorrência entre leucose enzoótica e brucelose em búfalos (Bubalus bubalis) em sistema de produção extensivo ${ }^{1}$
}

\author{
Nancyleni P. Chaves ${ }^{2 *}$, Danilo C. Bezerra², Larissa S. dos Santos², Janaira S. Sá2, \\ Hamilton P. Santos ${ }^{2}$ e Hélder de M. Pereira ${ }^{2}$
}

\begin{abstract}
Chaves N.P., Bezerra D.C., Santos L.S., Sá J.S., Santos H.P. \& Pereira H.M. 2012. [Intercurrence of enzootic leucosis and brucellosis in buffaloes (Bubalus bubalis) in extensive production system.] Intercorrência entre leucose enzoótica e brucelose em búfalos (Bubalus bubalis) em sistema de produção externsivo. Pesquisa Veterinária Brasileira 32(2):131-134. Laboratório de Diagnóstico de Doenças Infecciosas, Universidade Estadual do Maranhão, Cidade Universitária Paulo VI, Cx. Postal 9, Tirical, São Luís, MA 65055-970, Brazil. E-mail: nancylenichaves@hotmail.com

This study was carried out to evaluate the intercurrence of brucellosis and enzootic leucosis in buffaloes in extensive production system by establishing the prevalence of reagent buffaloes for specific diagnostic tests. We analyzed 232 animals serologically by the technique of double immunodiffusion in agarose gel (AGID) for diagnostic of leucosis and the tampon acidified antigen (TAA) test, followed by confirmatory tests of 2-mercaptoethanol (2-ME) and slow serum agglutination (SSA) in tubes for diagnostic of brucellosis. The prevalence of buffaloes that were positive for leucosis and brucellosis tests were $4.21 \%$ $(10 / 232)$ and $5.18 \%(12 / 232)$ respectively. The results of this investigation indicated that the diseases occur in the population studied, however, with low prevalence and without depending on the occurrence of both.
\end{abstract}

INDEX TERMS: Brucella abortus, VLEB, bubalines , Maranhão.

RESUMO.- Objetivou-se com este estudo avaliar a intercorrência entre leucose enzoótica e brucelose em búfalos (Bubalus bubalis) em sistema de produção extensivo, pelo estabelecimento da prevalência de bubalinos reagentes às provas diagnósticas específicas. Foram analisados sorologicamente 232 animais, pela técnica de imunodifusão dupla em gel de agarose para diagnóstico de leucose enzoótica e o teste do antígeno acidificado tamponado, seguida pelos testes confirmatórios 2-mercaptoetanol e soroaglutinação lenta em tubos para diagnóstico de brucelose. As prevalências de búfalos que apresentaram positividade para leucose e brucelose foram $4,21 \%(10 / 232)$ e $5,18 \%$ $(12 / 232)$, respectivamente. Os resultados obtidos nesta pesquisa permitiram concluir que as infecções estudadas encontram-se presentes na população avaliada, entretanto, com baixa prevalência e sem dependência de ocorrência entre ambas.

\footnotetext{
${ }^{1}$ Recebido em 10 de setembro de 2011.

Aceito para publicação em 11 de outubro de 2011.

${ }^{2}$ Laboratório de Diagnóstico de Doenças Infecciosas, Universidade Estadual do Maranhão (UEMA), Cidade Universitária Paulo VI, Cx. Postal 9, Tirical, São Luís, MA 65055-970, Brasil. *Autor para correspondência: nancylenichaves@hotmail.com
}

TERMOS DE INDEXAÇÃO: Brucella abortus, VLEB, bubalinos, Maranhão.

\section{INTRODUÇÃO}

A leucose enzoótica e a brucelose são doenças infecto-contagiosas cosmopolitas, caracterizadas pela evolução crônica e por grandes prejuízos que determinam à pecuária bovina nacional ao comprometerem a performance produtiva dos rebanhos, reduzindo a produção, estabelecendo sucessivas condenações de carcaças em matadouros e restringindo o comércio de animais, além do aumento dos custos com serviços veterinários (Paulin \& Neto 2003, Silva et al. 2008, Barros Filho et al. 2010).

A hipótese da intercorrência da leucose com doenças bacterianas vem sendo postulada (Melo et al. 2000, Mendes et al. 2011) sob a fundamentação de dois fatores que podem interferir de forma interdependente e associada na etiopatogenia das doenças envolvidas, como: manejo sanitário a que são submetidos os rebanhos e as características imunológicas do Vírus da Leucose Enzoótica Bovina (VLEB) (Mendes et al. 2011).

O papel do VLEB no desencadeamento de bacterioses oportunistas de importância clínico-epidemiológica e em 
saúde pública, como a brucelose, é desconhecido. Admite-se, entretanto, que o comprometimento da integridade do sistema imunológico pela ação imunodepressora do VLEB, que penetra e incorpora-se no genoma linfócitário por tempo indeterminado (Castro et al. 1988), associado a evidências imunocitológicas de que infecta monócitos circulantes (Heeney et al. 1992) aumenta a susceptibilidade do hospedeiro a outras infecções (Burny \& Mammerickx 1987).

Adicionalmente, estresse do hospedeiro advindo da vida produtiva (lactação e maximização de ganho de peso) e, principalmente, de doenças intercorrentes, desempenha, provavelmente, importante papel no desencadeamento da replicação dos retrovírus no organismo infectado, condição clínico-imunitária que inclui o VLEB e sua ampla disseminação nos rebanhos bovinos (Wyers 1975, Mendes et al. 2011).

Nesse contexto potencialmente crítico, em que infecção e doença representam praticamente o mesmo risco na cadeia epidemiológica, uma realidade cada vez mais presente nos rebanhos é o alastramento do vírus e a iminência da instalação de um estado de enzootia da brucelose. É preciso, pois, a implementação sistemática de medidas sanitárias que visem o diagnóstico e o controle dessas enfermidades (Mendes et al. 2011).

Diante do exposto, enfatizando a importância do conhecimento dessas enfermidades, realizou-se este estudo com o objetivo de avaliar a intercorrência entre leucose enzoótica e brucelose em rebanhos bubalinos da Baixada Maranhense.

\section{MATERIAL E MÉTODOS}

\section{Área de estudo}

0 estudo foi realizado em rebanhos bubalinos criados na Baixada Maranhense. Esta região está localizada na porção noroeste do Estado do Maranhão ( $1^{\circ} 00^{\prime}-4^{\circ} 00^{\prime} \mathrm{S}$ e $44^{\circ} 21^{\prime}$ - $45^{\circ} 21^{\prime} \mathrm{W}$ ), abrange extensas áreas sujeitas a inundações e, apresenta tensão ecológica entre as formações de cocais ao Sul; cerrados a Leste; floresta Amazônia a Oeste e sistemas marinhos a Norte (Santos 2004).

A economia da baixada Maranhense é baseada em atividades agropecuárias, onde predomina a tradicional pecuária extensiva de gado de corte, concentrada em médios e grandes produtores, e a dinâmica e expansiva pecuária leiteira, concentrada em pequenos e médios produtores. Esta região detém o maior rebanho bubalino do estado do Maranhão com um efetivo de 48.305 animais e confere ao estado do Maranhão o segundo lugar no cenário nacional na produção desta espécie animal (Maranhão 2010).

\section{Animais}

A população estudada foi constituída por fêmeas bubalinas com aptidão para corte, mestiças da raça Murrah, não imunizadas contra brucelose, com idade superior a 24 meses (Brasil 2001, 2004, 2006).

\section{Delineamento amostral}

0 tamanho da amostra foi estabelecido em função de alguns critérios epidemiológicos como, tipo de exploração, categoria animal e a área geográfica, utilizando-se a técnica de amostragem preconizada pelo Centro Panamericano de Zoonoses (1988) e pelo Centro Panamericano de Febre Aftosa (Astudillo 1979), relacionados ao estudo de prevalência das enfermidades crônicas infecciosas.
As propriedades de exploração pecuária envolvidas neste estudo encontravam-se submetidas a práticas de manejos semelhantes, onde os rebanhos eram criados de forma extensiva. As propriedades apresentavam limitados recursos técnicos e baixa rotatividade de animais.

Para a determinação do número de amostras bubalinas a ser examinada foi estabelecido 16,0\% como a prevalência mínima estimada da infecção por vírus da leucose enzoótica bovina (Tenório 2003), admitindo-se uma margem de erro de $20 \%$, depositando-se nesse resultado um grau de confiança de $95 \%$, desta forma, obteve-se 232 como número mínimo de amostras a serem testadas.

\section{Colheita das amostras de sangue}

As amostras foram colhidas no período de julho a dezembro de 2010, por meio de venopunção da jugular, após antisepsia e com auxílio de agulha descartável 40 x 12 mm, sendo acondicionadas em tubos de ensaio estéreis que permaneceram inclinados e em repouso para facilitar a retração do coágulo até o processamento laboratorial. Foram centrifugadas durante 15 minutos com força real de centrifugação igual a 2000G e o soro obtido foi transferido para tubos plásticos e armazenado à $-20^{\circ} \mathrm{C}$.

Durante a coleta das amostras foi aplicado questionário epidemiológico para obtenção de informações referentes às propriedades, aos animais estudados e ao manejo sanitário.

\section{Testes diagnósticos}

As análises sorológicas foram realizadas no Laboratório de Diagnóstico de Doenças Infecciosas do Curso de Medicina Veterinária da Universidade Estadual do Maranhão (UEMA).

Leucose enzoótica bovina (LEB). As amostras séricas foram examinadas pela Imunodifusão Radial Dupla de Ouchterlony-IDGA-LEB (Birgel 1982), reconhecida mundialmente para detecção de anticorpos séricos específicos anti-VLEB, por meio de um substrato de difusão gelatinoso utilizando-se antígeno glicoproteico (gp 51), extraído do envelope do vírus da leucose enzoótica bovina e produzido pelo Instituto de Tecnologia do Paraná - TECPAR. A leitura foi realizada 72 horas após a montagem do sistema.

Brucelose. 0 Antígeno Acidificado Tamponado (AAT) foi realizado como teste de triagem para detecção de anticorpos anti- Brucella utilizando antígeno produzido pelo TECPAR.

As amostras reagentes no AAT foram submetidas simultaneamente ao 2-Mercaptoetanol (2-ME) e Soroaglutinação Lenta em Tubos (SAL) utilizando antígeno produzido pelo TECPAR. A interpretação dos resultados foi realizada mediante a legislação em vigor (Brasil 2004).

\section{Análise de dados.}

Os resultados obtidos foram analisados através do programa Instat 2.0 versão 2003, considerando um nível de significância de $5 \%(\mathrm{P} \leq 0,05)$. Inicialmente foi procedida a análise de contigência usando-se o teste de Fischer para verificar a existência de dependência entre as variáveis Leucose Enzoótica e Brucelose. Neste caso, quando o valor de P fosse inferior a 5\% rejeitar-se-ia a hipótese de independência, indicando existência de relação (associação) entre essas duas variáveis.

\section{RESULTADOS}

Das 232 amostras de búfalos (Bubalus bubalis) avaliadas no estudo para diagnóstico de leucose enzoótica $4,31 \%$ $(10 / 232)$ foram positivas.

Em relação à brucelose, a prevalência de búfalos reagentes ao teste do Antígeno Acidificado Tamponado foi de 
$5,18 \%(12 / 232)$. As amostras positivas neste teste foram submetidas aos testes confirmatórios (2-mercaptoetanol e soroaglutinação lenta em tubos) e, todas reagiram positivamente, com títulos de anticorpos que variaram de 1:100 a 1:200, confirmando a infecção nestes animais.

Na população estudada, a prevalência de búfalos reagentes simultaneamente aos testes IDGA e sorológico para brucelose foi $0,87 \%(2 / 232)$. A análise de contigência por meio do teste exato de Fischer demonstrou independência na ocorrência entre as duas enfermidades $(\mathrm{P}>0.05)$.

\section{DISCUSSÃO}

Este é o primeiro relato de anticorpos anti-VLEB em búfalos (Bubalus bubalis) no Estado do Maranhão.

Os critérios preconizados por Shettigara (1986) permitiram avaliar que a população avaliada apresentou prevalência classificada como de baixa intensidade e, que a leucose enzoótica mantém-se em índices baixos em bubalinos da Baixada Maranhense, entretanto, estes resultados evidenciam que o VLEB está circulando na população estudada.

A baixa frequência observada nesta pesquisa pode estar associada, possivelmente, aos fatores clássicos de influência relacionados ao manejo, a gênese da doença e a sua dinâmica clínico-epidemiológica (DiGiacomo 1992, Mendes et al. 2011). De um modo geral, a baixa prevalência pode ter ocorrido também em função do refinamento racial ou do grau de mestiçagem dos rebanhos, uma vez que os animais avaliados eram na totalidade mestiços da raça Murrah.

A raça é um atributo que interage em condições naturais, de forma indissociável, com as normas de criação. Classicamente, têm-se estabelecido que a doença ocorra com mais frequência no rebanho leiteiro refinado (raças leiteiras) por ser manejado de forma mais intensiva quando comparado aos rebanhos criados de forma extensiva. 0 sistema de criação intensivo origina lotação exagerada das criações, além de ser submetido a manipulações tecnológicas, que mal aplicadas facilitam a transmissão horizontal (principalmente as formas iatrogênicas) ou vertical (transplacentária) do VLEB (Mendes et al. 2011).

Neste estudo, os resultados obtidos, demonstraram que a baixa disseminação do vírus nos animais estudados, considerando a semelhança do manejo implementado, ocorreu, provavelmente, pelo baixo fluxo de animais nas propriedades, bem como pela baixa introdução de animais importados de outros estados e países. Moraes et al. (1996) sugerem que a introdução da infecção pelo VLB no rebanho brasileiro está associada à importação de animais positivos de outros países.

Foi observado desconhecimento dos produtores sobre leucose, assistência médico-veterinária deficiente, além da ausência de um programa de sanidade animal que contemple a erradicação desta enfermidade que interfere de forma negativa na produtividade dos rebanhos.

Os resultados demonstram que a brucelose encontra-se em baixos índices nos rebanhos bubalinos avaliados. Esse valor foi equivalente aos dados oficiais que indicam a prevalência de animais soropositivos para brucelose entre 4 e 5\% (Brasil 2006), bem como levantamentos anteriores realizados no Maranhão para bovinos (Santos et al. 2007).
A baixa frequência para anticorpos anti-Brucella abortus identificada no estudo deve-se aos efeitos de um conjunto de ações sanitárias oficiais conduzidas ao longo das últimas décadas em praticamente todas as regiões do país.

Positividade simultânea aos testes IDGA e sorológico para brucelose indica presença de bubalinos potencialmente infectados e fontes naturais do VLB e/ou de Brucella abortus nos rebanhos, entretanto, não foi verificada associação entre essas duas variáveis $(\mathrm{P}>0,05)$, o que reforça a hipótese de independência destas enfermidades no rebanho estudado.

Infecção e doença representam mesmo risco na cadeia epidemiológica da LEB e brucelose, logo, os bubalinos, portadores inaparentes de infecção, são elementos precursores da gênese das duas doenças na população examinada, sendo seu reconhecimento indispensável para projeção do problema, possibilitando o mapeamento de focos e a antecipação de medidas mais efetivas de combate por meio de programas sanitários oficiais (Mendes et al. 2011).

Os animais infectados podem apresentar diminuição da produtividade, representar condenações de carcaças em matadouros, restrições comerciais e aumento dos custos com serviços veterinários. Além disso, considerando o caráter irreversível da infecção pelo VLEB e Brucella abortus associado ao caráter zoonótico da brucelose, para o saneamento de rebanhos, os bubalinos reagentes devem ser sacrificados, o que implica em prejuízos para os produtores.

A presença de anticorpos anti-VLEB e anti-Brucella abortus representa deterioração das condições de saúde dos animais examinados, pertencentes basicamente a pequenos produtores, os quais, ao recorrerem a mecanismos alternativos de atenção Médico Veterinária ou tentarem obter ganhos comerciais, promovem o trânsito e tráfico de bovinos infectados entre suas criações, podem disseminar estes agentes no Estado do Maranhão.

\section{CONCLUSÕES}

Os resultados obtidos nesta pesquisa, considerando a análise e interpretação dos aspectos sanitários da leucose e da brucelose nos rebanhos bubalinos examinados, permitiram concluir que a prevalência encontrada para ambas as enfermidades foi baixa.

Entretanto, a presença de anticorpos anti-VLEB e anti-Brucella abortus indica que os agentes etiológicos estão circulando na população bubalina da Baixada Maranhense e representam alerta aos serviços de vigilância veterinária pelo risco iminente de comprometimento da saúde dos rebanhos bubalinos e, pelo caráter zoonótico da brucelose.

A infecção simultânea de poucos animais sugere que o VLB desempenha pouca influência no desencadeamento da brucelose bubalina.

\section{REFERÊNCIAS}

Astudillo V.M. 1979. Encuesta por muestra para estudios epidemiologicos en populaciones animales. Serie de Manuales Didáticos n. 12, Centro Panamericano de Febre Aftosa, Rio de Janeiro.60p.

Barros Filho I.R., Guimarães A.K., Sponchiado D., Krüger E.R., Wammes E.V., Ollhoff R.D., Dornbusch P.T. \& Biondo A.W. 2010. Soroprevalência de anticorpos para o vírus da leucose enzoótica em bovinos criados na 
região metropolitana de Curitiba, Paraná. Arqs Inst. Biológico, São Paulo, 77(3):511-515.

Birgel E.H. 1982. Leucose linfática enzoótica dos bovinos adultos: aspectos clínicos e diagnóstico, p.249-260. In: Ibid. (Ed.), Patologia Clínica Veterinária. Sociedade Paulista de Medicina Veterinária, São Paulo, SP. (Resumo)

Brasil 2001. Inquérito Soroepidemiológico da Brucelose: manual de procedimentos. Programa Nacional de Controle e Erradicação da Brucelose e Tuberculose Animal (PNCEBT), MAPA/SDA/DDA, Ministério da Agricultura, Pecuária e Abastecimento, Brasília. 24p.

Brasil 2004. Instrução Normativa № 06, de 8 de janeiro de 2004. Aprova o Regulamento Técnico do Programa Nacional de Controle e Erradicação da Brucelose e Tuberculose Animal. Secretaria de Defesa Agropecuária, Ministério da Agricultura, Pecuária e Abastecimento, Brasília. Disponível em: http://www.agricultura.gov.br. Acesso em 20 jun. 2011.

Brasil 2006. Manual Técnico. MAPA/SDA/DAS, Ministério da Agricultura, Pecuária e Abastecimento. Programa Nacional de Controle e Erradicação da Brucelose e Tuberculose Animal (PNCEBT), Brasília. 184p.

Burny A. \& Mammerickx M. 1987. Enzootic bovine leukosis and bovine leukemia virus. Developments in Veterinary Virology, Bibliography Series III. Ed. Boston, EUA. 282p.

CEPANZO 1988. Procedimentos para estudios de prevalencia de enfermedades cronicas por muestreo. Centro Panamericano de Zoonosis, Buenos Aires. 33p.

Castro N.H.C., Walter J., Santos R.C.S., D’Angelino J.L., Benesi F., Birgel E.H. $\&$ Beçak W. 1988. Cytogenetics study of cattle affected by persistent lymphocythosis. J. Vet. Med. 35:380-384.

DiGiacomo R.1992. The epidemiology and control of Bovine Leukemia Virus. Vet. Med. 87:248-257

Heeney J.L., Valli P.J., Jacobs R.M. \& Valli V.E. 1992. Evidence for bovine leukemia virus infection of peripheral blood monocytes and limited antigen expression in bovine lymphoid tissue. Lab. Invest. 66(5):608-617.

Maranhão 2010. Estratificação do rebanho do Estado do Maranhão: relatório final de vacinação dos bovinos contra febre aftosa no Estado do Maranhão. Programa de Prevenção e Erradicação da Febre Aftosa, Coordenadoria de Defesa Animal, Agência Estadual de Defesa Agropecuária do Estado do Maranhão, São Luís.
Melo L.E.H., D’Angelino J.L., Castro R.S., Freitas A.A., Silva F.F., Santos N.V.M., Rêgo E.W., Schalch U.M., Pacheco J.C.G., Benatti L.A.T. \& Tenório T.G.S. 2000. Avaliação da intercorrência entre leucose enzoótica, tuberculose e leptospirose dos bovinos em rebanhos leiteiros de São Paulo. Anais 27을 Conbravet, Águas de Lindóia, SP, p.24. (Resumo)

Mendes E.I., Melo L.E.H., Tenório T.G.S., Sá L.M., Souto R.J.C., Fernandes A.C.C., Sandes H.M.M. \& Silva T.I.B. 2011. Intercorrência entre leucose enzoótica etuberculose em bovinos leiteiros do Estado de Pernambuco. Arqs Inst. Biológico, São Paulo, 78(1):1-8.

Moraes M.P., Weiblen R., Flores E.F., Rebelatto M.C., Zanini N., Rabuske M., Hübner S.O. \& Pereira N.M. 1996. Levantamento sorológico da infecção pelo vírus da Leucose Bovina nos rebanhos leiteiros do Estado do Rio Grande do Sul, Brasil. Ciência Rural 26:257-262.

Paulin L.M. \& Ferreira Neto J.S. 2003. 0 Combate à brucelose bovina: situação brasileira. Funep, Jaboticabal. 154p.

Santos O.M. 2004. Avaliação dos usos e ocupação das terras da Bacia Hidrográfica do Rio Pericumã/MA, utilizando como parâmetros os padrões recomendáveis para uma área de proteção ambiental. Dissertação de Mestrado, Universidade Federal do Maranhão, São Luís. $126 \mathrm{p}$.

Santos H.P., Teixeira W.C., Oliveira M.M.M., Pereira H.M., Oliveira R.A., Negreiros R.C., Soares Filho P.M., Santana S.S. \& Castro R.S. 2007. Brucelose bovina e humana diagnosticada em matadouro municipal de São Luís/ MA, Brasil. Ciênc. Vet. Tróp. 10(2/3):86-94.

Shettigara P.T. 1986. Eradication of bovine leukemia virus infection in commercial dairy herds using the agar gel immuno-diffusion test. Can. J. Vet. Res. 50:221-226.

Silva R.C., Fontana I., Meirelles F.C., Rug-Giero A.P.M., Benato N. \& Borges J.R.J. 2008. Ocorrência de leucose enzoótica bovina na forma de linfossarcomas no distrito federal: relato de caso. Arqs Inst. Biológico, São Paulo, 75(4):507-512.

Tenório T.G.S. 2003. Aspectos sanitários da leucose enzoótica, da leptospirose e da brucelose dos bovinos em rebanhos leiteiros de Pernambuco. Dissertação de Mestrado, Universidade Federal Rural de Pernambuco, Recife, 143p.

Wyers M. 1975. Rappel sur les oncornavirus des animaux. Rec. Méd. Vét. 151(3):153-163. 